\title{
DR-25. MOLECULAR COMPLEX OF QUERCETIN WITH GLYCYRAM
}

\author{
L.A. Yakovishin, E. N. Korzh \\ Sevastopol State University, University St., 33, Sevastopol, 299053, Russia \\ E-mail: chemsevntu@rambler.ru
}

Quercetin (Quer) is one of the most famous flavonols, being an aglycone of rutin [1]. Quer was founded in grapes, buckwheat, apples, tea, citrus, bilberries, blackberries, and other plants. Quer and rutin have P-vitamin activity. They reduce permeability and fragility of capillaries. Quer also exhibits antioxidant, anti-inflammatory, antispasmodic, antisclerotic, diuretic, and antitumor effects. Glycyram (monoammonium salt of triterpene glycoside glycyrrhizic acid, GC) is an anti-inflammatory and antiallergic drug. The molecular complexation of glycyrrhizic acid and GC with different drugs and biologically active molecules is widely studied [2-4].

A new molecular complex of GC with Quer in a 1:1 molar ratio was obtained. The synthesis of GC-Quer complex was carried out in the liquid phase (in a mixture of $96 \%$ aqueous ethanol and chloroform at a $1: 1$ ratio, $\mathrm{v} / \mathrm{v})$. The obtained mixture was incubated at $50{ }^{\circ} \mathrm{C}$ for $1,5 \mathrm{~h}$ with continuous stirring.

The complexation was studied by ATR IR Fourier spectroscopy with diamond crystal plate. It was shown that hydrogen bonds are formed between the components of the molecular complex $\left(-\mathrm{C}=\mathrm{O}_{\mathrm{GC}} \cdots \mathrm{H}-\mathrm{O}{ }_{-}{ }_{\text {Quer }}\right.$ and $-(\mathrm{H}) \mathrm{O} \cdots \mathrm{H}-\mathrm{O}-)$.

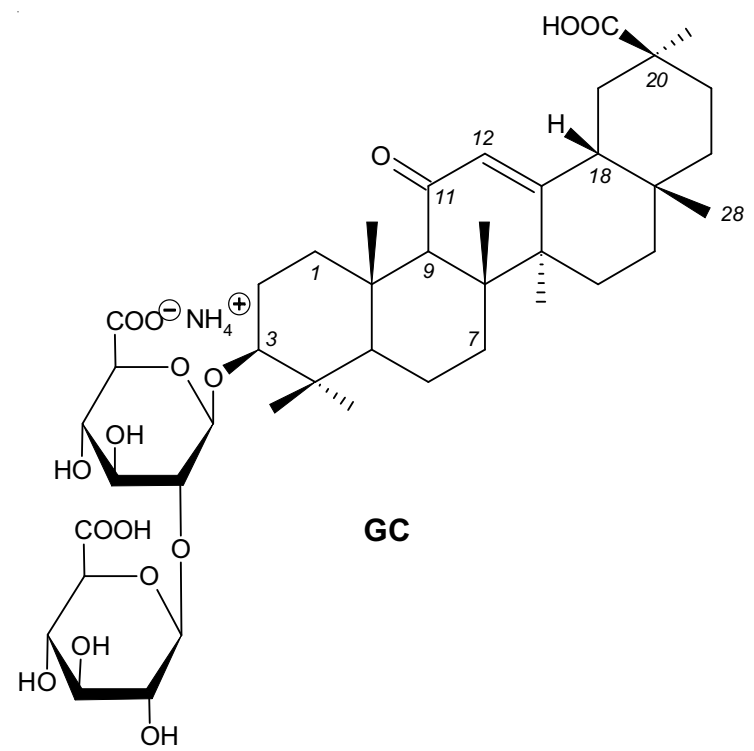<smiles>O=c1c(O)c(-c2ccc(O)c(O)c2)oc2cc(O)cc(O)c12</smiles>

\section{References}

1. Boots A. W., Haenen G. R., Bast A. Health effects of quercetin: From antioxidant to nutraceutical // Eur. J. Pharmacol. Elsevier, 2008. Vol. 585, № 2/3. P. 325.

2. Yakovishin L. A., Grishkovets V. I. Ivy and Licorice Triterpene Glycosides: Promising Molecular Containers for Some Drugs and Biomolecules // Stud. Nat. Prod. Chem. Elsevier, 2018. Vol. 55. P. 351.

3. Tolstikova T., Khvostov M., Bryzgalov A. The Complexes of Drugs with Carbohydrate-Containing Plant Metabolites as Pharmacologically Promising Agents // Mini-Reviews Med. Chem. 2009. Vol. 9, № 11. P. 1317.

4. Polyakov N. E. Glycyrrhizic Acid as a Novel Drug Delivery Vector: Synergy of Drug Transport and Efficacy // The Open Conference Proceedings Journal. 2011. Vol. 2, № 1. P. 64.

This research was supported by the Russian Foundation for Basic Research (Project № 18-43-920002). 